\title{
The Degree of Principals' Practice of Leadership Skills from the Perspective of UNRWA School Teachers
}

\author{
Bassam O. Ghanem ${ }^{1} \&$ Ferial M. Abu Awwad ${ }^{2}$ \\ ${ }^{1}$ School of Educational and Psychological Sciences, Amman Arab University, Amman, Jordan \\ ${ }^{2}$ School of Educational Sciences, The University of Jordan, Amman, Jordan \\ Correspondence: Bassam O. Ghanem, School of Educational and Psychological Sciences, Amman Arab \\ University, Amman, Jordan.
}

Received: March 4, 2019

doi:10.5539/ies.v12n7p106
Accepted: April 29, 2019 Online Published: June 29, 2019

URL: https://doi.org/10.5539/ies.v12n7p106

\begin{abstract}
The goal of this study is to determine the degree of leadership skills practiced by principals at UNRWA schools. In order to achieve this goal a questionnaire consisting of 56 items was developed, which included two domains: Administrative and Technical skills, and personal and social skills. This questionnaire had been verified in terms of its validity and reliability. The study sample consisted of 400 male and female teachers, distributed according to gender into 185 male and 215 females from UNRWA schools. The main results of the study revealed that the mean score on the administrative and technical skills was 126.63 with a percentage of $77 \%$ and on the personal and social skills 77.3 with a percentage of $67 \%$. However, the mean score of the total score was 203.93 with a percentage of $73 \%$ which means that the degree of principals' practice of leadership skills was in average. Also, the results showed that there were statistically significant differences between the mean scores of the sample on the administrative and technical skills due to gender variable in favor of females. The study ended with some recommendations relating to enhance the principal's skills in general and for male principals specifically.
\end{abstract}

Keywords: leadership skills, principals, teachers, UNRWA schools

\section{Introduction}

Reviewing the previous researches and studies indicated that a successful school leader influences students' achievement in many important ways, whether through their impact on people or through the benefits of their institutions and their impact on school processes. There are many basic leadership practices: development of individuals by empowering teachers and other staff to do their work effectively, providing appropriate intellectual support and motivation to improve work, providing examples of practice and support, monitoring organizational performance, enhancing effective communication, redesigning the enterprise by adopting a productive school culture, modifying organizational structures that disrupt work, and building collaborative processes.

The results of researches and studies in this recent years confirmed the importance of three aspects of the principal's work; developing a deep understanding of how to support teachers, managing the curriculum in a way that promotes student learning, and developing the ability to transform schools into more effective institutions that promote teaching and learning for all students (Davis, Hammond, LaPointe, \& Meyerson, 2005).

In fact, there is no comprehensive theory of leadership, because of the tremendous expansion of leadership thinking. There is a range of different theories about leadership. All of which focus on the characteristics of leaders. For example, the leader sees things from multiple aspects and not only from a two-sided aspect, and the ability to understand and deal with other people's behaviors. Leaders need to work in a world that shares power. This requires an understanding of the social, political and economic data that they must deal with. This also requires knowledge of how to build teams and strengthen the humanitarian aspects of the educational institution. Of course, the leaders must be able to communicate with the recipient, and he must redraft a model of human relations, and may require some reflective thinking in his basic beliefs about work, self, and power. It may also require changing the traditional structures and systems of the institution, such as those relating to compensation, promotion, and other aspects of motivation. It could be difficult and time-consuming to achieve. Leaders also seek to know how to correct things. Things cannot be resolved right away, but different theories, techniques and methods can be applied to increase the effectiveness of operations. The leader can find and develop new ideas and 
guidelines in practice, and be willing to work on redesigning the operations and infrastructure of the institution, in a new gradual way, helping him to transform the school into a learning organization. A learning organization is a skilled organization in establishing, acquiring, transferring knowledge and modifying behavior to reflect new knowledge and visions (Evans, 2000).

There is no doubt that the lack of necessary leadership skills for the school leader is a problem, a gap between actual leadership and required leadership is a serious responsibility. The educational institutions adapt by refocusing efforts to develop leadership and priorities, both individually and tactically. The leader tends to align professional development experience with organizational goals. For example, leaders who have good skills in guiding and motivating individuals have sufficient knowledge of how to effectively handle and delegate responsibilities to employees, expand employee skills and development, act fairly, invest their talents and creativity, translate the vision of the institution to realistic work action plans. An efficient leader who has the skill to articulate long-term goals and strategies develops plans to make balance between long-term goals with immediate needs, update plans to reflect changing circumstances, and develop contingency plans that include future changes (Leslie, 2009).

When we talk about leadership, we certainly mean leadership skills. They are the tools, behaviors, and abilities that an individual need to be successful in guiding and motivating others. It means helping others to develop their abilities and capabilities. The successful leader is the one who drives others to achieve their own successes. There are three basic characteristics, which each successful leader must possess; the first is the desire to lead. Without this desire, the leader will not be successful in performing his roles. The second is the commitment to both the vision and mission of the institution. Otherwise, he cannot convince his staff to work towards achieving goals. In addition, the third is integration (Leadership Skills, 2010).

It is important to note that leadership is associated with the process of making change, a term that applies to a very diverse set of individual behaviors - may be equally distributed among those that relate to the initiation and management of change, and those that provide continuity change and direction. Leadership involves learning together and constructing meaning and knowledge collectively and collaboratively. It involves beliefs, values, attitudes, information and assumptions, which means generating ideas together, seeking reflection on meaning, working in the light of common new beliefs and information, and actions that emerge with this system. This means that leadership is socially and culturally sensitive (Marturano \& Gosling, 2008).

However, the principals have to interact with many people, including students, teachers, parents and school board officials, regardless of the country from which he came, culture, or preparedness. He will need to be able to work with people in all of these groups to accomplish the school's goals. He has to be a boss to teachers, establishing clear goals to give them direction. Also, need to be approachable, so that others feel comfortable when talking to him, while remaining professional and authoritative as the head of the school.

\subsection{Introduce the Problem}

The present study attempted to investigate the leadership skills of school principals from the perspective of a sample of school teachers in UNRWA staff. The problem of the current study can be treated by answering the following main question: what is the degree of principals' practice of leadership skills from the perspective of UNRWA school teachers?

From this main question the following questions were derived:

1) What is the degree of principals' leadership skills from the perspective of UNRWA school teachers?

2) Are there any statistical significant differences at the level perspective $(\alpha=0.05)$, in the degree of principals' leadership skills, from the perspective of UNRWA school teachers, due to the gender of the teacher, the years of experience, academic qualifications, and specialization.

\subsection{Importance of the Problem}

This study draws the attention of principals, and teachers to the most prominent leadership skills that they can develop independently or externally. This study also draws attention to the leadership skills required by all school principals in the educational areas, and the educational stages covered by the study. Also, the results of this study can provide training and development centers with information they can depend on to hold courses and programs that can contribute to the development of these practices and skills.

In general, researchers as well can make benefit of the results of this study, by using the instrument of this study to their own environment, and they can make comparison studies according to the different cultures and environments. 


\subsection{Terminology of the Study}

The terms of the study are defined as follows:

Leadership skills: the skills that must be exercised by the principals of the school as an educational leader, to affect the performance of teachers and staff at school.

Administrative and technical skills: These are related to the administrative and technical supervisory fields, and include many tasks related to discipline, planning, control, accountability and evaluation. They are measured by the scores obtained by the respondents on this subscale.

Personal and social skills: These skills are related to the personal and social fields, and include many tasks related to cooperation and belonging, sincerity and attention to human aspects, perseverance, and openness of mind and acceptance. They are measured by the scores obtained by the respondent on this subscale.

\subsection{Describe Relevant Scholarship}

Jackson (2018) conducted a study that aimed to identify patterns in elementary teachers' perceptions of their principals' leadership skills related to student achievement and elementary principals' perceptions of their own leadership practices and compare those perceptions. The conceptual framework for this qualitative case study design was instructional leadership. Twelve teachers of Kindergarten to Grade 5 from 3 high-achieving elementary schools volunteered to participate and provided data through 2 focus groups with 6 primary grade teachers and 6 intermediate grade teachers respectively. Principals at the same 3 high-achieving elementary schools provided data through semi structured interviews. Open coding and thematic analysis yielded 4 themes from the principals' responses, including instructional leadership, hands-on leadership, communication and collaboration, and management by visibility. The teachers' responses resulted in the themes of high expectations for student achievement, a supportive learning environment, consistent collection and review of student achievement data, and an overall positive school climate to promote exemplary instructional practices and student success. A positive social change that can stem from this study is implementing principal leadership practices related to the findings in low-achieving schools. This may result in student achievement, leading to increase academic and economic opportunities.

Wieczorek and Manard (2018) report on a phenomenological study of the leadership experiences of six novice, rural public-school principals in a midwestern U.S. state. They situated the analysis within existing research on leadership for learning, particularly how novice principals interpreted instructional leadership challenges in the context of rural school leadership. The findings indicated that principals worked to balance their professional and private lives and were challenged to meet their community's expectations to be visible and engaged. To meet districts' constrained budgetary circumstances, the principals also maintained overlapping district- and building-level responsibilities. The principals focused heavily on developing relationships and trust among their teachers, students, and parents. The implications of this study demonstrate a need to develop new leaders' understanding of rural school community expectations; develop skills to fulfill expanding job responsibilities; and supplement leadership preparation, mentoring, and professional development programs regarding the specialized needs of rural school leaders.

Trujillo (2018) identified coaching models that would be critical in guiding principals to become transformational leaders. The study identified three coaching models for principals to share their beliefs about coaching and effective leadership practices. The coaching models supported the concept of helping effective leaders reach their next level of competence with clarified thinking or meaningful action to achieve ongoing goals. This was a qualitative phenomenography research study. The researcher conducted interviews with $15 \mathrm{~K}-8$ principals by sharing scenarios of leaders receiving support from three different coaching models. The coaching models utilized were transforming coaching, cognitive coaching and peer coaching. An analysis of the qualitative data revealed the following recommendations. It is recommended school districts provide principals coaching support to become transformational leaders by utilizing effective coaching models and effective leadership practices.

Abu-Shreah and Zidan (2017) conducted a study that aimed to know the degree of schools principals practicing innovation and its relationship with the teachers' professional development; the population of the study was consisted of all male and female teachers numbering 415 teachers. The sample of the study is consisted of 205 male and female teachers from members of the study population. To achieve the goals of the study two questionnaires were developed in order to collect information to define the degree of the schools principles practicing innovation and its relation with the teachers' professional development; the first questionnaire contained the degree of the schools principles practicing innovation; the first questionnaire is consisted of 24 paragraphs, the second questionnaire contains the measurement of the degree of the teacher's practicing professional development 
which was consisted of 37 paragraphs whom their validity and consistency are checked. The study concluded that the degree of schools principals practicing innovation and its relation with the teachers' professional development in the three domains was great arranged in accordance with the study domains as follows: encouraging of innovative ideas, promoting of schooling environment and solving of innovative problems. The study results showed as well that the degree of schools teachers' professional development was great according to the teachers' point of view. The result of the study revealed a positive correlation of statistical significance at the level $(\alpha=0.05)$ among the averages of schools teachers estimations in the domains of schools principals practicing innovation and their estimations of the teachers professional development. In the light of the results the study recommended the work to meet the required new training for the schools principals; to conduct the field studies on the effectiveness of the training programs provided to the schools principals and to the teachers and to increase the appropriate material and nominal motivations for the innovators of them.

Saleh and Abu Mokh (2017) conducted a study that aimed to reveal the elementary teachers' practicing degree of leadership skills from the perspectives of teachers themselves within the green line in Palestine, in light of learning organization and organizational culture. To achieve this aim, the researchers prepared two instruments; the first was a questionnaire composed of (52) items to find out the practicing degree of leadership skills from the perspectives of teachers themselves. It consisted of four domains. The second was a questionnaire including (34) items to find out the learning organization and organizational culture's degree of implementation from the perspectives of teachers. The study sample was (230) teachers. The study results and findings revealed that the elementary teachers' practicing degree of leadership skills from the perspectives of teachers was high overall. The skills were as follows: Personal skills, administrative skills, perceptive skills, and humanitarian social skills respectively. It revealed also that there were no statistical differences among the means of the elementary teachers' practicing degree of leadership skills from the perspectives of teachers due to the variables of gender, academic rank, experience, and school. Elementary school implementation of learning organization and organizational culture from the perspectives of teachers was high. Moreover, there was a positive correlation between practicing leadership skills along with other domains and school implementation of learning organization and organizational culture from the perspectives of teachers.

Alberto, Waiyakarn, and Alberto (2016) conducted a study that aimed to determine the level of importance of the key competencies of principals in terms of the following domains: policy and direction, teaching and learning, staff, partnerships and managing resources, to determine the significant differences in the level of importance of the competencies as perceived by administrators, academic and non- academic support staff, and faculty and to investigate the significant relationship among the competencies. The population of this study consisted of 95 international schools. Convenience sampling was used to select 105 respondents from six (6) schools. A questionnaire was developed and pilot tested to determine its validity and reliability. The research investigation yielded these results: The highest level of importance of the competencies of principals in international schools was in the domain of "policy and direction". The lowest was in the "teaching and learning" domain. There were no significant differences in the level of importance of the key competencies of principals as perceived by administrators, academic and non-academic support staff and faculty. Significant relationships were found among the five (5) competencies of principals in international schools.

Abu Zaiter (2009) conducted a study aimed at identifying the degree of practicing leadership skills among secondary school principals in Gaza governorates from the point of view of secondary school teachers and ways to develop their practices. The study consisted of (76) applied to a sample of (832) teachers and secondary school in Gaza governorates. The main results of the study were the following: The level of leadership of high school principals was high. There were no statistically significant differences between the mean scores of the teachers 'estimations to the degree of their principls' leadership skills in general due to gender variable, while there were differences in leadership skills due to the variable of the educational area in favor of the East Gaza area, with no differences due to the variable number of years of service as a teacher.

Mohammed (2008) conducted a study aimed at evaluating the efficiency of the administrative performance of the principals of public and private schools in Ibb. The results of the study indicate that the administrative performance of managers of public schools in all administrative functions, including planning, organization, direction and evaluation, And the weakness of the follow-up evaluation of the performance of the directors of public schools supervisors, and the marginalization of the role of the principal of reward and punishment and the spirit of competition between school principals, and weak training material by the Ministry of Education, where A focus on the functions of basic management, and organizes training programs sensitive methods that are more effective, away from traditional lectures, and do not be called for the establishment and implementation of training university professors specialized material in the science of management, poor government school principals rely on school 
regulations during the exercise of administrative work.

Al-Ghamdi (2007) conducted a study aimed at identifying the level of leadership skills available to secondary school principals in the Al-Baha region in Saudi Arabia and developing these skills available to managers in order to improve the school work (308 managers (273) and teachers (35) for the small size of the original community in Al-Baha area). The study found the following important results: Managers have a high level of strategic leadership skills in general but the formulation of the strategic objectives of the work methods in a measurable manner and setting the time limit to achieve each of the objectives of the plan was medium. There is no difference between managers and teachers in their assessment of the level of availability of skills Strategic Leadership in Managers Except for enriching school activities for strategic ideas and managers' ownership, the clear outlook for Saudi secondary education is different in assessing the level of these skills. The quality of managers in general, except self-training, the identification of training needs, the application of the concepts of total quality, and the establishment of professional development workshops were medium. Quality, development of technical skills in self-training, and attention to the overall quality of work they differ in the assessment of these three skills.

\section{Method}

\subsection{Sample}

The sample of the study consisted of 400 male and female teachers of UNRWA schools in the year 2018, distributed by gender into 185 males and 215 females and representatives as far as possible for the specialization variable. Table 1 shows the distribution of the sample according to the study variables.

Table 1. Distribution of sample members by study variables: gender, years of experience, qualification and specialization

\begin{tabular}{cccc}
\hline & Variables & Frequency & Percentage $\%$ \\
\hline \multirow{4}{*}{ Specialization } & Scientific Subjects & 103 & 26 \\
& Humanistic Subjects & 197 & 49 \\
& Administration and IT & 100 & 25 \\
Experience & Less than 5 y & 109 & 27 \\
& 5-10 y & 99 & 25 \\
Qualification & More than 10 y & 192 & 48 \\
& Bachelor & 353 & 88 \\
Gender & Graduate studies & 47 & 12 \\
& Male & 185 & 46 \\
& Female & 215 & 54 \\
\hline
\end{tabular}

\subsection{Instrument}

The study used one instrument, which is leadership skills questionnaire, consisting of (56) items divided into two parts, the first: administrative and technical skills (33 items), and the second: personal and social skills (23 items). The questionnaire includes 12 negative and 44 positive items, it was arranged in 5-point likert scale with the following categories: very low (1 point), low ( 2 points), medium ( 3 points) high ( 4 points), very high ( 5 points), the scores are reversed in the case of negative items.

The total score on the first part (administrative and technical skills) ranged between 33 and 165, the score on the second part (personal and social skills) ranged between 23 to 115, and the total score on the instrument ranged between 56 and 280. Table 2 shows the subscales of the questionnaire with their items.

Table 2. The parts of the questionnaire with their items

\begin{tabular}{lcc}
\hline Parts & \# items & \\
\hline Administrative and technical skills & 33 & $1-33$ \\
Personal and social skills & 23 & $34-56$ \\
\hline
\end{tabular}

\subsubsection{The Psychometric Characteristics of the Study Instrument}

The validity and reliability of the study instrument has been verified using the following methods:

1) The Validity of the Study Instrument 
The content validity of the tool has been verified by presenting it to five experienced and competent arbitrators in the fields of education, psychology and school administration. Their opinions were reviewed, studied and made appropriate in terms of the accuracy of the formulation, the correctness of the language and the clarity of the items, which was prepared for him, noting that the amendments were limited to the linguistic aspects and no item was deleted. Discrimination indices of the items were investigated by using item-total correlation. Table 3 shows these results:

Table 3. Discrimination indices of the items by using item-total correlation

\begin{tabular}{|c|c|c|}
\hline Item number & Correlation with first subscale scores & Correlation with second subscale scores \\
\hline 1. & $0.72 * *$ & \\
\hline 2. & $0.73 * *$ & \\
\hline 3. & $0.74 * *$ & \\
\hline 4. & $0.70 * *$ & \\
\hline 5. & $0.67 * *$ & \\
\hline 6. & $0.74 * *$ & \\
\hline 7. & $0.64 * *$ & \\
\hline 8. & $0.67 * *$ & \\
\hline 9. & $0.57 * *$ & \\
\hline 10. & $0.69 * *$ & \\
\hline 11. & $0.78 * *$ & \\
\hline 12. & $0.32 *$ & \\
\hline 13. & $0.69 * *$ & \\
\hline 14. & $0.64 * *$ & \\
\hline 15. & $0.35^{*}$ & \\
\hline 16. & $0.44 * *$ & \\
\hline 17. & $0.71 * *$ & \\
\hline 18. & $0.82 * *$ & \\
\hline 19. & $0.79 * *$ & \\
\hline 20. & $0.85 * *$ & \\
\hline 21. & $0.74 * *$ & \\
\hline 22. & $0.44 * *$ & \\
\hline 23. & $0.93 * *$ & \\
\hline 24. & $0.77 * *$ & \\
\hline 25. & $0.78 * *$ & \\
\hline 26. & $0.78 * *$ & \\
\hline 27. & $0.79 * *$ & \\
\hline 28. & $0.83 * *$ & \\
\hline 29. & $0.83 * *$ & \\
\hline 30. & $0.85 * *$ & \\
\hline 31. & $0.81 * *$ & \\
\hline 32. & $0.73 * *$ & \\
\hline 33. & $0.29^{*}$ & \\
\hline 34. & & $0.65 * *$ \\
\hline 35. & & $0.69 * *$ \\
\hline 36. & & $0.72 * *$ \\
\hline 37. & & $0.71 * *$ \\
\hline 38. & & $0.68 * *$ \\
\hline 39. & & $0.40^{*}$ \\
\hline 40. & & $0.41^{*}$ \\
\hline 41. & & $0.69 * *$ \\
\hline 42. & & $0.40^{*}$ \\
\hline 43. & & $0.58 * *$ \\
\hline 44. & & $0.63 * *$ \\
\hline 45. & & $0.73 * *$ \\
\hline 46. & & $0.71 * *$ \\
\hline
\end{tabular}




\begin{tabular}{cc}
\hline 47. & $0.73^{* *}$ \\
48. & $0.42^{* *}$ \\
49. & $0.39 *$ \\
50. & $0.60^{* *}$ \\
51. & $0.58^{* *}$ \\
52. & $0.48^{* *}$ \\
53. & $0.40^{*}$ \\
54. & $0.38^{*}$ \\
55. & $0.57^{* *}$ \\
56. & $0.54^{* *}$ \\
\hline
\end{tabular}

$* *$ sig at $0.01 ; *$ sig at 0.05 .

Table 3 shows that correlation coefficients between the items in each subscale and the total score on the subscale which they belong to range between .32 and .93) for the first subscale and between .38 and .76 for the second subscale, to which they all belong are positive.

2) Reliability of the Study Instrument

The study reliability was verified using two ways:

Internal consistency by using the Cronbach alpha equation, and the split half using the Spearman-Brown equation, on a pilot sample consisting of (37) teachers from outside the study sample. Table (4) shows reliability coefficients.

Table 4. Reliability coefficients by using the Cronbach alpha equation, and the split half using the Spearman-Brown equation

\begin{tabular}{lcc}
\hline Subscales & Cronbach Alpha & Split half \\
\hline Administrative and Technical Skills & 0.96 & 0.94 \\
Personal and Social Skills & 0.91 & 0.94 \\
Total Instrument & 0.97 & 0.90 \\
\hline
\end{tabular}

Table 4 shows that the total reliability coefficient of the scale equal ( 0.97$)$ by using the internal consistency method (Cronbach Alpha) and (0.90) by using the split half method. The reliability coefficients of the subscales of the study instrument ranged between 0.91 and 0.96 in the manner of internal consistency, and 0.94 in split half-method, all indicators are appropriate for the reliability of the study tool.

\section{Results}

To answer the first question, the mean scores and standard deviations of the scores obtained by the study subjects were extracted.

To answer the second question, the means and standard deviations, the MANOVA variance analysis, and the scheffe test were obtained for post-comparisons.

Criteria for judging the degree of leadership skills for each item of the study instrument have been established based on the number of categories used in the tool. Table 5 shows these criteria

Table 5. Criteria on one paragraph of the questionnaire

\begin{tabular}{lccc}
\hline Value & Less than 2 & 2 to 4 & More than 4 \\
\hline The level of practice & low & average & high \\
\hline
\end{tabular}

Results of question 1: What is the degree of principals' leadership skills from the point of view of UNRWA schoolteachers?

To answer this question, the means and the standard deviations of scores were extracted on each of the subscales and the total score. Table 6 shows these results. 
Table 6. Means and standard deviations of the scores of the study sample members on each of the subscales and the total score

\begin{tabular}{lccc}
\hline Leadership skills & Means & Standard deviations & Percent \% \\
\hline Administrative and technical skills & 126.63 & 22.62 & $77 \%$ \\
Personal and social skills & 77.30 & 14.22 & $67 \%$ \\
Total instrument & 203.93 & 33.70 & $73 \%$ \\
\hline
\end{tabular}

Table 6 shows that the means scores on the administrative and technical skills part was (126.63) with a percentage of $(77 \%)$ and on the personal and social skills subscale (77.3) with a percent of (67). However, the mean on the total score was (203.93) with a percentage of (73\%) with average level.

The means and the standard deviations of scores were also extracted on each item of each part separately. Tables 7 and 8 show these results.

Table 7. The means and the standard deviations of scores on the first part (administrative and technical skills)

\begin{tabular}{|c|c|c|c|c|}
\hline No & Items & Means & $\begin{array}{c}\text { Standard } \\
\text { deviations }\end{array}$ & Level \\
\hline 1. & Understands the environment in which he works & 4.21 & 0.88 & High \\
\hline 2. & Improve the investment of assets where he works & 4.10 & 0.92 & High \\
\hline 3. & Engages the staff in setting school goals & 3.86 & 1.02 & Average \\
\hline 4. & $\begin{array}{l}\text { Is interested in obtaining the information necessary for his work } \\
\text { from reliable sources }\end{array}$ & 4.06 & 0.92 & High \\
\hline 5. & Striving for innovation, and creativity in his field of work & 3.93 & 1.02 & Average \\
\hline 6. & Translates the school's vision and mission into realistic plans & 3.84 & 0.96 & Average' \\
\hline 7. & Develop a detailed and accurate plan for something he wants to do & 4.03 & 0.90 & High \\
\hline 8. & His/her plans are realistic & 3.90 & 0.97 & Average' \\
\hline 9. & Has extensive management skills & 3.92 & 1.02 & Average' \\
\hline 10. & Is keen to develop his managerial skills permanently & 4.04 & 0.90 & High \\
\hline 11. & Organizes the priorities of his work according to the objectives set & 4.02 & 0.90 & High \\
\hline 12. & works alone and does not delegate his powers to employees & 2.96 & 1.33 & Average' \\
\hline 13. & Be careful to organize and manage time accurately & 3.93 & 0.95 & Average' \\
\hline 14. & Organize his files and records appropriately & 4.39 & 0.77 & High \\
\hline 15. & Spends a lot of time doing office work & 3.93 & 1.02 & Average' \\
\hline 16. & Conducts too many school meetings & 3.51 & 0.96 & Average' \\
\hline 17. & Is keen to form work teams in the school. & 3.99 & 0.96 & Average' \\
\hline 18. & $\begin{array}{l}\text { Is keen to raise the cognitive and professional competencies of the } \\
\text { employees }\end{array}$ & 3.95 & 0.95 & Average' \\
\hline 19. & $\begin{array}{l}\text { Distributes tasks to the staff at the school according to their } \\
\text { capabilities }\end{array}$ & 3.86 & 1.04 & Average' \\
\hline 20. & $\begin{array}{l}\text { Helps employees understand their tasks and responsibilities in } \\
\text { different ways }\end{array}$ & 3.92 & 0.99 & Average' \\
\hline 21. & Involves the employees in making work decisions & 3.72 & 1.06 & Average' \\
\hline 22. & $\begin{array}{l}\text { Tells the staff what they should do, but leaves them free to } \\
\text { implement }\end{array}$ & 3.79 & 1.01 & Average' \\
\hline 23. & Encourages his/her employees to work actively and dynamically & 3.89 & 1.04 & Average' \\
\hline 24. & React positively to any new ideas proposed by the staff & 3.82 & 1.10 & Average' \\
\hline 25. & $\begin{array}{l}\text { Seeks to create a high moral spirit among all employees in the } \\
\text { school }\end{array}$ & 3.83 & 1.10 & Average' \\
\hline 26. & $\begin{array}{l}\text { Be careful to set an example in adhering to regulations and } \\
\text { instructions }\end{array}$ & 4.03 & 0.96 & High \\
\hline 27. & Has agreed standards in his/her dealings with employees & 3.90 & 0.98 & Average' \\
\hline 28. & Investigates justice in his/her assessment of staff performance & 3.94 & 1.02 & Average' \\
\hline 29. & Has active and able to bear different working conditions & 4.04 & 0.98 & High \\
\hline 30. & Has the ability to confront crises and act wisely towards them & 3.95 & 1.02 & Average' \\
\hline 31. & Act quickly in situations that require decisive decisions & 3.87 & 1.04 & Average' \\
\hline 32. & Has the courage to make decisive decisions & 3.83 & 1.13 & Average' \\
\hline
\end{tabular}


33. Blames others for failing in some school tasks

Table 7 shows that the means of the items on the administrative and technical skills subscale ranged from 2.77 (item 33) to 4.39 (item 14). However, the degree of the skills on most of the items of this domain was average, except for eight items were the degree of practice on them is high.

Table 8 . The means and the standard deviations of scores on the second part (personal and social skills)

\begin{tabular}{|c|c|c|c|c|}
\hline No & Items & Means & $\begin{array}{c}\text { Standard } \\
\text { deviations }\end{array}$ & Level \\
\hline 1. & Know how to speak and communicate his message to others easily & 4.13 & 0.96 & High \\
\hline 2. & Listens to those who talk to him/her until the end without interruption & 3.93 & 1.08 & Average' \\
\hline 3. & Provides opportunities for employees to express their opinions freely & 3.96 & 1.02 & Average' \\
\hline 4. & Collaborates with hard people easily & 3.81 & 1.06 & Average' \\
\hline 5. & Respects the opinions and decisions of others & 4.13 & 2.58 & High \\
\hline 6. & Gets very angry if someone breaks his/her orders & 2.80 & 1.32 & Average' \\
\hline 7. & Threats the employees usually & 2.36 & 1.37 & Average' \\
\hline 8. & Shows confidence in those who deal with him/her & 3.83 & 1.04 & Average' \\
\hline 9. & Reminds the staff always that he/she is the manager & 2.69 & 1.35 & Average' \\
\hline 10. & Peaceful and never opposed & 2.90 & 1.28 & Average' \\
\hline 11. & Able to control his/her emotions and adjust it & 3.89 & 1.02 & Average' \\
\hline 12. & $\mathrm{He} / \mathrm{she}$ is interested in enhancing communication among school staff & 3.87 & 1.04 & Average' \\
\hline 13. & Works to strengthen school-community relations & 4.01 & 1.01 & High \\
\hline 14. & is patient in his/her pursuit of goals & 3.90 & 1.01 & Average' \\
\hline 15. & Is always preoccupied with his/her own interests during the work & 2.36 & 1.38 & Average' \\
\hline 16. & He deals with the workers harshly & 2.22 & 1.35 & Average' \\
\hline 17. & Know the conditions of those working with him & 3.75 & 1.09 & Average' \\
\hline 18. & Self-esteem without arrogance & 3.58 & 1.16 & Average' \\
\hline 19. & $\begin{array}{l}\text { His/her personal problems are often reflected in his/her work and } \\
\text { relationship with staff }\end{array}$ & 2.21 & 1.36 & Average' \\
\hline 20. & His/her actions matches his/her saying permanently & 3.65 & 1.09 & Average' \\
\hline 21. & Complain constantly and grumble of everything & 2.23 & 1.34 & Average' \\
\hline 22. & is keen to participate in the social events of employees & 3.95 & 1.11 & Average' \\
\hline 23. & $\begin{array}{l}\text { treats the staff with humanity, taking into account their different } \\
\text { circumstances }\end{array}$ & 4.12 & 1.11 & High \\
\hline
\end{tabular}

Table 8 shows that the means of the items on the personal and social skills part ranged between 2.21 (item 19) to 4.13 (item 5). However, the degree of the skills on most of the items of this domain was average, except for four items were the degree of practice on them is high.

However, the results illustrated that the degree of schools' principals of leadership skills in view of teachers was average in general, that could be attributed to the view of teachers who are not in touch with all tasks which are customized to principals; and their responses may be affected by their previous experiences with their schools' principals, in addition to their subjective observation sometimes.

This result may be partially different with the study of Abu Zaiter (2009) which found that the level of leadership of high school principals was high.

Results of question 2: Are there any statistical effect at the level $(\alpha=0.05)$, on the degree of principals' leadership skills from the perspective of UNRWA schoolteachers, according to the gender difference of the teacher (male and female), the years of experience (less than 5 years, 5 to 10 years, more than 10 years), his academic qualifications (bachelor's and graduate studies), and his specialization (scientific materials, human literature, computer and management)?

To answer this question, the means and the standard deviations of scores on each of the parts and the total score were calculated according to the variables of the study as follows: 


\section{1) Gender}

Table 9. Means and standard deviations of the scores of the study sample members on each of the parts and the total score according to gender

\begin{tabular}{|c|c|c|c|c|c|}
\hline Variables & Sex & $\mathrm{N}$ & Mean & Std. Deviation & Std. Error Mean \\
\hline \multirow{3}{*}{$\begin{array}{l}\text { Administrative and } \\
\text { skills }\end{array}$} & Male & 185 & 123.0108 & 21.03594 & 1.54659 \\
\hline & Female & 215 & 129.7488 & 23.51103 & 1.60344 \\
\hline & Male & 185 & 78.1514 & 13.34935 & .98146 \\
\hline Personal and Social skills & Female & 215 & 76.5581 & 14.91957 & 1.01751 \\
\hline \multirow{2}{*}{ Total } & Male & 185 & 201.1622 & 31.52666 & 2.31789 \\
\hline & Female & 215 & 206.3070 & 35.37118 & 2.41229 \\
\hline
\end{tabular}

2) Experience

Table 10. Means and standard deviations of the scores of the study sample members on each of the parts and the total score according to experience

\begin{tabular}{llccc}
\hline Variables & & N & Mean & Std. Deviation \\
\hline \multirow{3}{*}{ Administrative and Technical skills } & Less than 5 y & 109 & 124.5688 & 26.51078 \\
& $5-10 \mathrm{y}$ & 99 & 123.1212 & 23.02717 \\
& More than 10 y & 192 & 129.6146 & 19.54555 \\
& Total & 400 & 126.6325 & 22.62415 \\
& Less than 5 y & 109 & 77.4404 & 16.55486 \\
Personal and Social skills & 5-10 y & 99 & 74.7778 & 15.21986 \\
& More than 10 y & 192 & 78.5104 & 11.99127 \\
& Total & 400 & 77.2950 & 14.21965 \\
Total & Less than 5 y & 109 & 202.0092 & 40.81020 \\
& 5-10 y & 99 & 197.8990 & 34.33999 \\
& More than 10 y & 192 & 208.1250 & 28.06472 \\
\hline
\end{tabular}

3) Qualification

Table 11. Means and standard deviations of the scores of the study sample members on each of the parts and the total score according to qualification

\begin{tabular}{|c|c|c|c|c|c|}
\hline & Qualify & $\mathrm{N}$ & Mean & Std. Deviation & Std. Error Mean \\
\hline \multirow{2}{*}{$\begin{array}{l}\text { Administrative } \\
\text { skills }\end{array}$} & Bachelor & 353 & 126.8357 & 22.53119 & 1.19921 \\
\hline & Mster or $\mathrm{PhD}$ & 47 & 125.1064 & 23.50322 & 3.42830 \\
\hline \multirow{2}{*}{ Personal and Social skills } & Bachelor & 353 & 77.5241 & 14.74307 & .78469 \\
\hline & Mster or $\mathrm{PhD}$ & 47 & 75.5745 & 9.33610 & 1.36181 \\
\hline \multirow{2}{*}{ Total } & Bachelor & 353 & 204.3598 & 34.15304 & 1.81778 \\
\hline & Mster or $\mathrm{PhD}$ & 47 & 200.6809 & 30.25623 & 4.41332 \\
\hline
\end{tabular}

4) Specialty 
Table 12. Means and standard deviations of the scores of the study sample members on each of the parts and the total score according to specialty

\begin{tabular}{llccc}
\hline & & N & Mean & Std. Deviation \\
\hline \multirow{4}{*}{ Administrative and Technical skills } & Scientific Subjects & 103 & 124.5243 & 22.05512 \\
& Humanistic Subjects & 197 & 124.9746 & 22.10537 \\
& Administration and IT & 100 & 132.0700 & 23.54504 \\
& Total & 400 & 126.6325 & 22.62415 \\
& Scientific Subjects & 103 & 77.0097 & 14.36806 \\
& Humanistic Subjects & 197 & 76.4213 & 13.57820 \\
& Administration and IT & 100 & 79.3100 & 15.21542 \\
& Total & 400 & 77.2950 & 14.21965 \\
& Scientific Subjects & 103 & 201.5340 & 33.83693 \\
& Humanistic Subjects & 197 & 201.3959 & 32.54378 \\
& Administration and IT & 100 & 211.3800 & 35.02979 \\
& Total & 400 & 203.9275 & 33.70426 \\
\hline
\end{tabular}

Tables $9,10,11$ and 12 show that there are observed differences between the mean scores of the sample on the parts and on the total scale according to the previous variables, to investigate its statistical significant differences, multiple analysis of variance MANOVA was used. Table 13 shows these results.

Table 13. The results of the Tests of Between-Subjects Effects MANOVA for the effect of the variables on the leadership skills

\begin{tabular}{|c|c|c|c|c|c|c|c|}
\hline Source & Dependent Variable & $\begin{array}{l}\text { Sum of } \\
\text { Squares }\end{array}$ & $\mathrm{df}$ & $\begin{array}{c}\text { Mean of } \\
\text { sume } \\
\text { Squares }\end{array}$ & $\mathrm{F}$ & Sig. & $\begin{array}{c}\text { Eta } \\
\text { Squared }\end{array}$ \\
\hline gender & Administrative and Technical & 3453.50 & 1 & 3453.50 & 7.00 & 0.01 & .017 \\
\hline $\begin{array}{l}\text { Wilks' Lambda } \\
.963 * *\end{array}$ & Personal and Social & 470.29 & 1 & 470.29 & 2.35 & 0.13 & .006 \\
\hline Experienc & Administrative and Technical & 2076.71 & 2 & 1038.35 & 2.10 & 0.12 & .011 \\
\hline $\begin{array}{l}\text { Wilks' Lambda } \\
.985\end{array}$ & Personal and Social & 891.44 & 2 & 445.72 & 2.23 & 0.11 & .011 \\
\hline Qualification & Administrative and Technical & 18.52 & 1 & 18.52 & 0.04 & 0.85 & .000 \\
\hline $\begin{array}{l}\text { Wilks' Lambda } \\
.995\end{array}$ & Personal and Social & 291.77 & 1 & 291.77 & 1.46 & 0.23 & .004 \\
\hline Specialization & Administrative and Technical & 2851.71 & 2 & 1425.86 & 2.89 & 0.06 & .014 \\
\hline $\begin{array}{l}\text { Wilks' Lambda } \\
.982\end{array}$ & Personal and Social & 426.58 & 2 & 213.29 & 1.07 & 0.35 & .005 \\
\hline \multirow{2}{*}{ Error } & Administrative and Technical & 194036.92 & 393 & 493.73 & & & \\
\hline & Personal and Social & 78700.94 & 393 & 200.26 & & & \\
\hline \multirow{2}{*}{ Corrected Total } & Administrative and Technical & 204228.98 & 399 & & & & \\
\hline & Personal and Social & 80677.19 & 399 & & & & \\
\hline
\end{tabular}

a. R Squared $=.050$ (Adjusted R Squared $=.035)$

b. $\mathrm{R}$ Squared $=.024$ (Adjusted R Squared $=.010)$

MANOVA revealed a significant multivariate main effect for gender; the results showed that there were statistically significant differences between the mean scores of the sample on the part of administrative and technical skills due to gender variable for the benefit of females. However, there are no significant effects for the other variables (experience, qualification, and specialty) on the subscales and total scale of leadership skills.

This result can be explained by the presence of certain common factors that contribute to the equivalence of the levels of the previous variables (experience, qualification, and specialty) went through similar cultural, social and economic educational conditions, in addition to the continuous training programs to enhance their skills.

This result was partially similar with the study of Abu Zaiter (2009) which found that there were no statistical significant differences between the mean scores of the teachers 'estimations to the degree of their principals' 
leadership skills in general due to gender variable, while there were differences in leadership skills due to the variable of the educational area in favor of the East Gaza area, with no differences due to the variable number of years of service as a teacher.

\section{Conclusions}

According to the previous results, we can conclude that the school principals have scientific qualifications, managerial skills and professional experience. They are selected according to a set of personal and professional standards. They are subject to administrative examinations, leadership interviews and courses in the field of leadership and administration work before they are chosen, and often the school principal has served as deputy principal, assistant headteacher or he was an active teacher.

However, school principals' commitment to work requirements makes them keen to exercise the leadership skills that enable them to fulfill the duties assigned to them, and the manager's sense of responsibility leads him to exercise his leadership duties to an appropriate degree.

\section{Recommendations}

- To enhance the leadership skills of school principals, especially in the items which were in average level.

- To concentrate on male schools and the leadership skills of their principals.

- To apply the current study tool to other educational regions and departments to explore the degree to which leadership managers practice leadership skills

- Conduct similar studies of the current study on leadership practices for managers from their own point of view

- Conduct similar studies on the degree of practice of educational supervisors for leadership skills

\section{Study Limitations}

The results of the present study have to be seen in the light of the following determinants:

- $\quad$ Male and female teachers of UNRWA schools.

- The subscales of the instrument: administrative and technical skills, and personal and social skills.

\section{References}

Abu Zaiter, M. (2009). Degree of development of secondary school principals in Gaza governorates for leadership skills and ways of developing them (Unpublished MA thesis). Islamic University, Gaza.

Abu-Shreah, M., \& Zidan, H. (2017). The Degree of Schools Principals Practicing Innovation and its Relation with the Teachers' Professional Development. Journal of Education and Practice, 8(8), 20-36.

Alberto, R., Waiyakarn, S., \& Alberto, M (2016). Competencies of Principals as Prioritized by Administrators, Faculty and Support Staff of International Schools in Bangkok, Thailand. https://doi.org/10.2139/ssrn.2771512

Al-Ghamdi, A. (2007). The level of leadership skills available and developed by high school principals in Al Baha, Saudi Arabia (Unpublished master thesis). University of Aden, Republic of Yemen.

Davis, S., Hammond, L., LaPointe, M., \& Meyerson, D. (2005). School Leadership Study Developing Successful Principals. Stanford Educational Leadership Institute

Evans, M. (2000). Course 18: Leadership. Retrieved from http://www.exinfm.com/training/pdfiles/course18.pdf

Jackson, S. (2018). Perceptions of Principal Leadership Skills in High-Achieving Elementary Schools (Dissertation, Walden University).

Leadership Skills. (2010). MTD Training \& Ventus Publishing ApS.

Leslie, J. (2009). What you need, and don't have, when it comes to leadership talent. Center for Creative Leadership.

Marturano, A., \& Gosling, J. (2008). Leadership: The key concepts. New York, NY: Routledge. https://doi.org/10.4324/9780203099643

Mohammed, A. (2008). Evaluating the efficiency of the administrative performance of the directors of public and private schools in Ibb city (Unpublished MA thesis). Ibb University, Republic of Yemen.

Saleh, A., \& Abu Mokh, M. (2017). The Practicing Degree of Leadership Skills by School Principals in the Green line in Palestine in Light of Learning Organization and Organizational Culture. International Journal 
for Research in Education, 41(1), 163-200.

Trujillo, C. (2018). Effective Leadership Attributes and Coaching Models for Principals (Dissertation, Northern Arizona University). ProQuest LLC, Ed.D.

Wieczorek, D., \& Manard, C. (2018). Instructional Leadership Challenges and Practices of Novice Principals in Rural Schools. Journal of Research in Rural Education, 34(2), 1-21. Retrieved from http://jrre.psu.edu/wp-content/uploads/2018/03/34-2.pdf

\section{Copyrights}

Copyright for this article is retained by the author(s), with first publication rights granted to the journal.

This is an open-access article distributed under the terms and conditions of the Creative Commons Attribution license (http://creativecommons.org/licenses/by/4.0/). 